\title{
A review of electromagnetic exploration Techniques and their applications in East Asia
}

\author{
Ping-Yu Chang ${ }^{1, *}$, Tada-nori Goto ${ }^{2}$, Xiangyun $\mathrm{Hu}^{3}$, and Evan $\mathrm{Um}^{4}$ \\ ${ }^{1}$ Department of Earth Sciences, National Central University, Taiwan \\ ${ }^{2}$ Department of Urban Management, Kyoto University, Japan \\ ${ }^{3}$ Institute of Geophysics and Geomatics, China University of Geosciences (Wuhan), China \\ ${ }^{4}$ Earth and Environmental Sciences, Lawrence Berkeley National Laboratory, USA
}

\section{Article history:}

Received 8 October 2020

Revised 5 November 2020

Accepted 5 November 2020

\section{Keywords:}

Electromagnetic method, Geophysical exploration, East Asia

\section{Citation:}

Chang, P.-Y., T. Goto, X. Hu, and E. Um, 2020: A review of electromagnetic exploration Techniques and their applications in East Asia. Terr. Atmos. Ocean. Sci., 31, 487-495, doi: 10.3319/ TAO.2020.11.05.01

\begin{abstract}
Electromagnetic (EM) exploration techniques, as powerful and important geophysical tools, have been extensively used in researches ranging from tectonics and resource exploration to environmental and engineering studies. These tools have also proven their applicability to such emerging fields as ocean and airborne surveys. In this article, we quantitatively and qualitatively review advances and applications of EM-exploration studies in East Asia during the past 20 years. During these last two decades, the field of electromagnetic exploration has grown fast, as shown in the increase in the number of related published articles. These studies focus mostly on the development of system platforms (space, aerial, marine) and on data-processing technologies (inversion algorithms, noise reduction). However, most EM applications have been limited to professional geophysics activities. Along with advances in electronics and sensor technologies, EM-exploration instruments are likely to evolve into a modularized open-access system that will become available to more and more scientists at lower and lower costs.
\end{abstract}

\section{INTRODUCTION}

Electromagnetic (EM) methods are techniques that have emerged in recent decades owing to the rapid development of electronic and information technologies. This development has made possible the modularization, miniaturization, and integration of EM field sensors, logger devices, and other tools. Improvements in computational power and imaging algorithms have increased the interpretation ability for measured signal responses. EM methods are based on the measurement of field variation induced by subsurface electromagnetic properties with coil receivers or dipole antennas placed on or above the earth's surface. Active EM methods use man-made EM sources, whereas passive EM methods use natural EM fields as their energy sources. Most active EM instruments are comprised of two or more sets of loops, coils, or antennas serving as transmitters and receivers. The response-field signals transmitted from the

\footnotetext{
* Corresponding author

E-mail:pingyuc@ncu.edu.tw
}

transmitter are then picked up by the receivers and used for interpretations of subsurface structures.

The use of EM induction for locating utility lines and faults in pipes or cables can be traced back to as early as the 1910s. Based on the changing electric field in grounded electrodes, the prototype of the transient EM method was proposed as "Eltran" prospecting (Fok and Bursian 1926; Klipsch 1939), which enables sounding tools to find subsurface targets. The first application of EM methods to ore and hydrocarbon exploration was performed by Karl Sundberg in the 1920s (Sundberg and Hedstrom 1934). In addition to active EM sounding, Japanese scientists in the 1930s first introduced a magnetotelluric (MT) technique that uses passive sources for exploration (Hatakeyama and Hirayama 1934; Hirayama 1934). In the 1960s, Paál (1965) observed that global navigation radio waves at a very low frequency (VLF) could be used to prospect for conductive mineral deposits, and the technology subsequently became the basis of the geophysical VLF method. The theory that 
underlies the VLF-EM technique was later described extensively in the literature (Paterson and Ronka 1971; Phillips and Richards 1975).

Although some EM methods were introduced first in East Asia in the 1930s (e.g., the MT method proposed in Japan), EM methods were not commercially available there until the 1960s (Reynolds 2011). Because EM methods have advanced rapidly in the last several years, attracting more and more attention from geoscientists and engineers, we would like to review the last twenty years of developments and applications of EM methods in East Asia. In addition, we will outline our impression of future trends in the development of EM methods.

\section{BASIC THEORY}

EM methods are based on Maxwell's equations:

$\nabla \cdot(\varepsilon E)=\rho$

$\nabla \cdot(\mu H)=0$

$\nabla \times E=-\frac{\partial(\mu H)}{\partial t}$

$\nabla \times H=\sigma E+\frac{\partial(\varepsilon E)}{\partial t}$

where $E$ and $H$ are the electric and magnetic fields, $\rho$ is electric-charge density, $\sigma$ is conductivity, $\mu$ is magnetic permeability, and $\varepsilon$ is dielectric permittivity.

From Maxwell's equations, one can derive the EM wave equations in the frequency domain:

$\nabla^{2} \bar{E}+\left(i \omega \mu \sigma-\omega^{2} \mu \varepsilon\right) \bar{E}=\nabla^{2} \bar{E}+\gamma^{2} \bar{E}=0$

$\nabla^{2} H+\left(i \omega \mu \sigma-\omega^{2} \mu \varepsilon\right) H=\nabla^{2} H+\gamma^{2} H=0$

where $\bar{E}$ and $\bar{H}$ are the electric and magnetic field strength, respectively, after the Fourier Transformation, and where $\gamma^{2}=\left(i \omega \mu \sigma-\omega^{2} \mu \varepsilon\right)$.

If we focus on the $\mathrm{x}$-polarized electric field, a general one-dimension solution to Eq. (5) is

$E_{x}(z)=E_{0} e^{-\gamma z}=E_{0} e^{-(\alpha-i \beta) z}$

In Eq. (7), $\alpha=[(\omega \sqrt{\mu \varepsilon}) / \sqrt{2}]\left[\sqrt{1+(\sigma / \omega \varepsilon)^{2}}+1\right]^{1 / 2}$ and $\beta=[(\omega \sqrt{\mu \varepsilon}) / \sqrt{2}]\left[\sqrt{1+(\sigma / \omega \varepsilon)^{2}}-1\right]^{1 / 2}$. A similar solution can be obtained for the y-polarized magnetic field for Eq. (6):
$H_{y}(z)=H_{0} e^{-\gamma z}=H_{0} e^{-(\alpha-i \beta) z}$

We can derive the phase velocity:

$v_{p h}=\frac{\omega}{\alpha}=\left\{\frac{\mu \varepsilon}{2}\left[\sqrt{1+\left(\frac{\sigma}{\omega \varepsilon}\right)^{2}}+1\right]\right\}^{-1 / 2}$

In the diffusive/quasi-static regime $(\varepsilon \omega \ll \sigma)$, the phase velocity can be simplified to

$v_{p h}=\sqrt{\frac{2 \omega}{\mu \sigma}}$

In the propagation regime $(\varepsilon \omega \gg \sigma)$, the phase velocity can be simplified to

$v_{p h}=\frac{1}{\sqrt{\mu \varepsilon}}$

Thus, EM waves move much more slowly in conductive and highly permeable media than in a propagation regime, and wave velocity is related to wave frequency in a diffusive regime. Most EM methods, such as the VLF method, the frequency-domain EM (FEM) method, the transient EM (TEM) method, and the MT method, operate in a diffusive regime at frequencies between DC and several hundred kHz. Because wave velocity is slow and because wavepropagation phenomena are hard to observe in a quasi-static regime, the aforementioned methods measure the diffusion of EM-field strength to estimate the EM properties in a subsurface. Their exploration depth can be approximated in relation to skin depth $(\delta)$, which indicates the depth at which field strength is decayed to $1 / \mathrm{e}$ of the source strength:

$\delta=\sqrt{\frac{2}{\omega \mu \sigma}}$

The methods using EM waves at different frequencies promote sounding ability at the subsurface because of the methods' different skin depths. Detailed descriptions regarding the VLF, FEM, TEM, and MT methods can be found in such textbooks as Nabighian (1988).

On the other hand, phase velocity is independent of the frequency in a propagation regime (normally for EM waves at frequencies higher than $10 \mathrm{MHz}$ for crustal materials). Since it is easier to observe the propagation phenomena of EM waves, researchers have used pulse EM waves to calculate travel time and its attenuation through reflected waves, such as the ground-penetrating radar (GPR) method (Baker et al. 2007; Annan 2009; Koppenjan 2009). 


\section{THE DEVELOPMENT AND APPLICATION OF EM METHODS IN EAST ASIA}

Over the past 20 years, the fields of EM exploration have grown quickly, as shown in the following analysis. Between the years 2000 and 2020, there were 1333 published research articles containing the keywords 'electromagnetic' + 'exploration' + 'geophysics' from ScienceDirect (https:// www.sciencedirect.com). This output of published EM research is impressive. When we narrow down our search to East Asian studies or authors, we find 359 published articles related to China, 141 articles related to Japan, 96 articles related to India, 37 articles related to South Korea, and 29 papers related to Taiwan, as shown in Fig. 1. A closer examination of Fig. 1 shows us that the overall published papers on EM exploration increased from 34 articles in 2000 to 142 articles in 2020. Figure 2, which compares variations in the growth of EM papers published throughout East Asia from 2000 to 2020, reveals that, although the trends varied annually according to region, the percentage of overall EM publications coming from China increased from about 9.3\% during the $2000-2005$ period to about $35.9 \%$ during the 2015 - 2020 period. By contrast, the percentage coming from Japan decreased significantly from $16.5 \%$ during the 2000 - 2005 period to $7.4 \%$ during the 2015 - 2020 period. As for South Korea and Taiwan, they held fairly steady at about $2 \%$ of overall published articles.

Our literature analysis clearly shows that research on EM methods is increasing worldwide and that this increase varies regionally. In East Asia, the research on EM methods has taken place in such fields as geology, engineering, risk assessment, natural resources, and environmental studies. Among the various aforementioned EM methods, the MT method can measure natural sources of MT fields at frequencies less than $1 \mathrm{~Hz}$. Tikhonov (1950) and Cagniard (1953) introduced the principles underlying the MT method, which, by inverting MT soundings, enables researchers to resolve resistivity structures up to several tens of kilometers below the earth's surface. Thus the MT method is commonly used for probing deep geological structures to shed light on tectonic settings (e.g., Chen and Chen 1998; Ryang et al. 1999; Fuji-ta et al. 2002; Han et al. 2009; Choi et al. 2013; Ikeda et al. 2013; Sun et al. 2019; Abdallah et al. 2020; Gao et al. 2020; Liang et al. 2020a, b; Ye et al. 2020; Zhang et al. 2020). The audio-frequency MT (AMT) method, working on natural or artificial EM signals with frequencies higher than $1 \mathrm{~Hz}$, provides good sounding resolution for resistivity structures at depths of a few kilometers. Researchers have used the AMT method, together with the TEM method, for ore, oil, and gas exploration owing to the methods' good sounding abilities within the necessary depth ranges (e.g., Chen et al. 2019; He et al. 2020; Hu et al. 2020; Liu et al. 2020a; Zeng et al. 2020).

Regarding the TEM method, it makes use of the pulse magnetic field to monitor the decay rate of the secondary field, in turn enabling researchers to interpret the subsurface structures (Nabighian and Macnae 1991). Some researchers who conduct subsurface exploration rely on the FEM method, which uses loop systems for transmitting and receiving continuous waves. The GPR uses EM pulses at a frequency range between $10 \mathrm{MHz}$ and $10 \mathrm{GHz}$ for non-destructive exploration and has a resolution up to a few centimeters. Therefore, the TEM, FEM, and GPR methods are already frequently used in various East Asian environmental investigations, some of which concern sea-water intrusion (e.g., Chen 1999; Mitsuhata et al. 2006), possible contamination from underground storage tanks (USTs) (e.g., Wang et al. 2015), and leachate leakage from landfills (e.g., Feng et al. 2020).

In engineering applications, East Asian researchers have used the TEM method for the detection of karst caves (Bin et al. 2017), which can prevent collapses due to tunnel boring. The GPR method, because it has higher resolution than other EM methods and works in a wave-propagation regime, is frequently used in engineering fields concerned with, for example, advance probing in tunnels ( $\mathrm{Li}$ et al. 2017).

\section{RECENT ADVANCES IN GEOPHYSICAL EM STUDIES}

In the past 20 years, researchers have devoted considerable effort to developing hardware and software for EM methods. Recently, East Asian researchers conducting airborne-based and marine-based exploration have been paying attention to EM devices, which are particularly efficient in survey projects. Developers have created various types of airborne TEM systems, including the airborne ZTEM system (Sasaki et al. 2014), the GREATEM system (Mogi et al. 2005), and the helicopter-borne VTEM system (Podgorski et al. 2013). These systems facilitate environmental research, such as mineral and volcano exploration. Owing to the recent rapid development of unmanned aerial vehicles (UAVs), TEM-based drone systems now exist and can operate in rough terrain, which is of particular importance in various parts of East Asia. For instance, Jomori et al. (2020) have suggested that drones can serve as a platform for TEM exploration. Liu et al. (2016) have introduced the SATEM UAV system and conducted a survey in East Ujimqin Banner, in northeast China. However, UAV-borne TEM measurements have given rise to several unresolved problems, including the small payloads and the short hovering times of the UAVs, UAV interference in EM devices, noise filtering in urban areas, the 3D inversion of received signals, and shallow exploration depths. Although there are airborne systems for frequency-domain EM and VLF exploration and UAVs equipped with GPR (e.g., Amiri et al. 2012; Altdorff et al. 2014), in East Asia they have not attracted as much attention as the TEM method owing to the fact that the former devices have much shallower exploration depths than 
airborne TEM systems. Because UAV-borne GPR and EM systems have shown their potential in landmine detection and other applications (e.g., Fernández et al. 2018; Šipoš and Gleich 2020), we expect to see booming development in these technologies throughout East Asia.

EM exploration technologies are installed not only on UAVs, but also in orbiting satellites and land rovers designed for the terrestrial exploration of planets and other natural orbiting bodies (e.g., the Moon). In outer space, EM satellites detect variations in EM fields, explore oceanic subsurface and rough terrains, and analyze precursors of earthquakes. This technology goes back decades: for example, the ALSE (Apollo Lunar Sounder Experiment) by NASA was a ground-penetrating radar experiment that flew on the Apollo 17 mission in 1972. Currently, the China SeismoElectromagnetic Satellite (CSES) is a joint venture between China and Italy analyzing seismic related phenomena such as EM perturbations as the SWARM satellites launched by European Space Agency. Moreover, GPR is becoming standard equipment on land rovers, and an example of lunarpenetrating radar is the Yutu-2 lunar rover, which was developed by China and has shown the subsurface structures in the Von Kármán crater on the Moon (Li et al. 2020a). In 2020, China, as well as the United States, individually

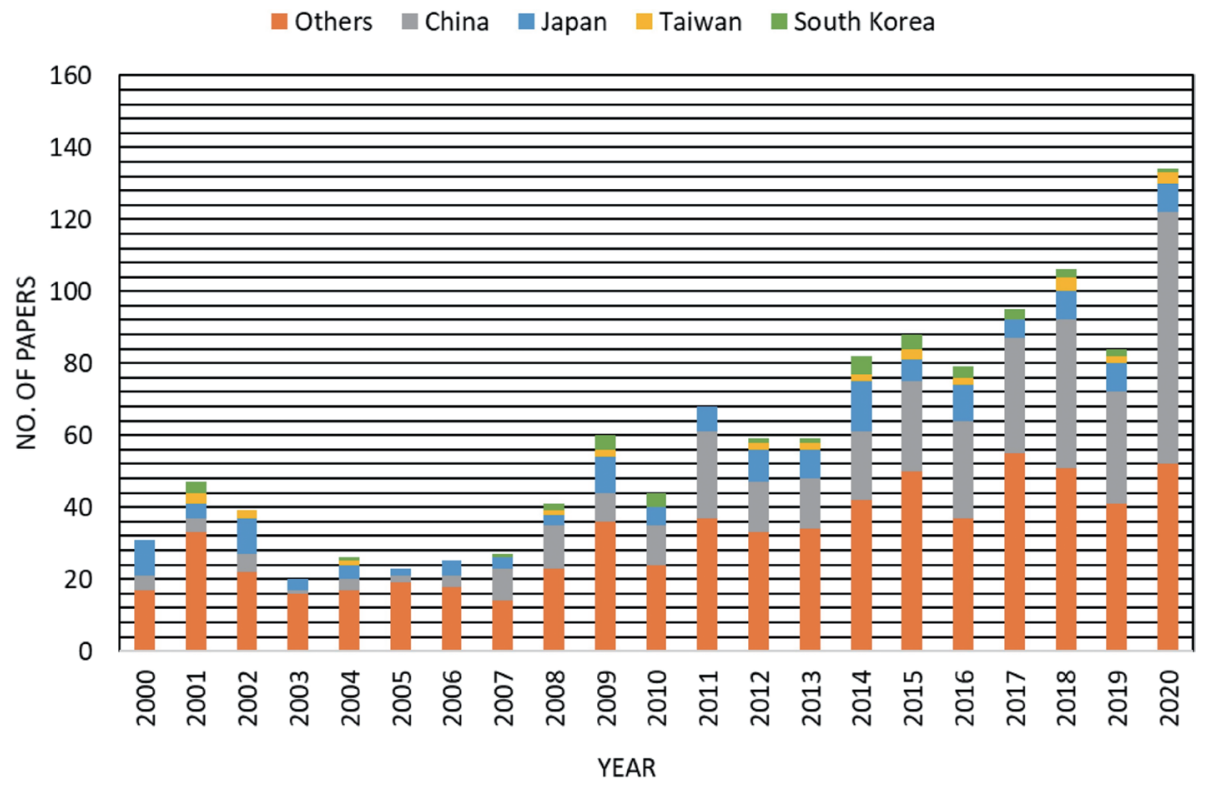

Fig. 1. The overall published papers regarding EM exploration from 2000 to 2020 in East Asia.

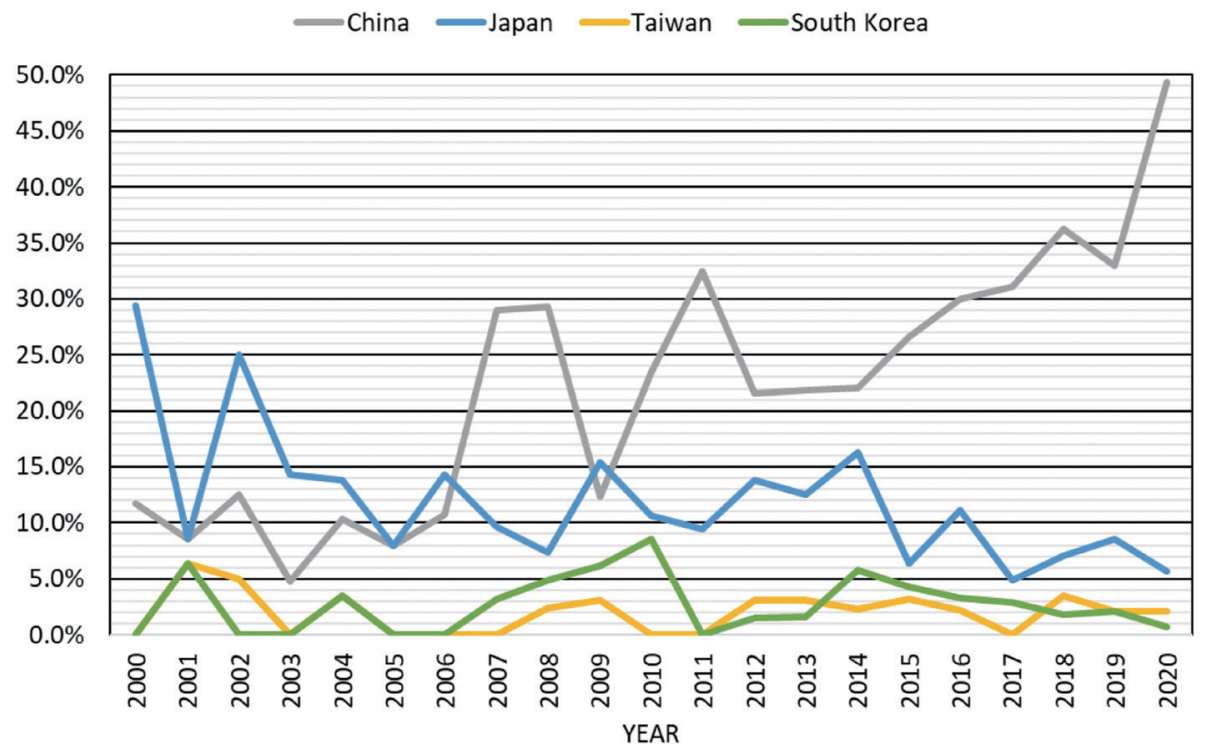

Fig. 2. The percentage of EM papers published in each of the four main East Asian countries between 2000 and 2020. 
launched two Mars land rovers carrying GPRs on board for the subsurface exploration of Mars.

In addition to airborne and satellite EM systems, marine EM technology has expanded significantly in East Asia and is admired for its potential in the hydrocarbon exploration of oceans. Detailed information regarding the development of marine EM technology can be found in the review paper by Constable (2013). In Asia, seafloor MT methods have been used for exploration in the Philippine Sea (Seama et al. 2007; Baba et al. 2010) and off the southwest coast of Taiwan (Hsu et al. 2014). Researchers have developed various self-surfacing seafloor MT systems for marine surveys (e.g., Kasaya and Goto 2009; Chen et al. 2015; Wang et al. 2017). In addition to deep-ocean MT systems, researchers in East Asia have developed shallow-water magnetotelluric systems for surveying depths less than $250 \mathrm{~m}$ off the coasts of Hokkaido, Japan (Ueda et al. 2014) and the Yellow sea (Duan et al. 2020).

Also notable in East Asia are advances in researchers' ability to interpret measurements. Frequency- and time-domain three-dimensional (3-D) inversions in relation to TEM and MT data have become popular in recent studies owing to their clarification of 3D structures (e.g., Ryang et al. 1999; Han et al. 2009; Choi et al. 2013; Noh et al. 2014; Sasaki et al. 2014, 2015; Sun et al. 2019; Zhang et al. 2020). Noisereduction technologies provide effective tools for filtering out environmental or artificial EM noises in various regions (e.g., Feng and Wang 2011; Key and Constable 2011; Wang and Liu 2017; Wang et al. 2017; Li et al. 2020b, c).

\section{PROSPECTS FOR EM EXPLORATION TECHNIQUES}

In the previous section, we reviewed recent studies regarding the development of EM exploration technologies in East Asia. In conclusion, we would like to note that these studies have focused on two central aspects: professionally developed system platforms (atmospheric, marine, spatial) and professionally developed data-processing technologies (inversion algorithms, noise-reduction).

Recently, rapid advances in electronics have given researchers an opportunity to create greater sensitivity, higher resolution, and less noise in EM systems adaptable to special environments. These advances include modifications to current sensing technologies and adaptations of new types of EM sensors for measurements. For example, Kai et al. (2017) have developed a new type of EM receiver by combining four capacitive electrodes and a triaxial induction coil for conducting EM observations in tunnels. In addition, new types of EM sensors, such as optical-fiber EM sensors (e.g., Sato and Takayama 2007; Layeghi et al. 2014), microelectromechanical system (MEMS) magnetic sensors (e.g., Campbell and Atekwana 2018), fluxgate magnetic sensors (e.g., Bartington and Chapman 2004; Ramasamy and Mo- hanty 2020), superconducting quantum interference devices (SQUIDs) (e.g., Du et al. 2018), and non-contact electric field instruments (e.g., Knudsen et al. 2017) also provide future alternative ways to measure electric and magnetic fields with lighter weights, smaller volumes, and better resolutions than are currently the norm.

However, many EM-exploration instruments around the world have been customized for special needs, and only trained professionals with customized codes can process relevant measurements. These obstacles make commercial EM instruments expensive and unyielding to users. Along with advances in electronic technologies, however, there are more electric and magnetic sensors, universal connectors, and multifunctional data loggers available than ever before in commercial markets. And open-access software packages for processing geophysical EM measurements, such as pyGIMLi (Rücker et al. 2017) and SimPEG (Cockett et al. 2015) in Python, are also available to the public. These software packages include modularized codes that can be integrated for data processing, with one-, two-, and threedimensional inversions or joint inversions available for geophysical data.

As a result, we would expect to have an open or modularized instrumentation structure that non-professionals will soon be able to adapt to and integrate into various EM projects. These systems are easily constructed with various sensors, transmitter antennas, loggers, and microcontrollers such as Arduino boards. Moreover, relevant data can be processed with low-cost open-access codes for the special needs of signal processing and inversion.

\section{AN INTRODUCTION TO THE EM STUDIES IN THE SPECIAL ISSUE}

To address the fast growing studies on the electromagnetic explorations, we initiated the special regarding the electromagnetic exploration Techniques and applications in the journal of Terrestrial, Atmosphere, and Oceanic Sciences. The special issue includes the EM characteristics studies that used to predicted the complex-resistivity behavior for the shales (Xu et al. 2020). In addision, Wang et al. (2020) and Yen et al. (2020) used of the resistivity imaging techniques in monitoring the remediation approaches and illuminating the subsurface conduits of mud volcanoes, respectively. Liu et al. (2020b) also discuss the use of the full-domain characteristics of the apparent resistivity in the applications with the tunnel-ground TEM method. Furthermore, Chang et al. (2020) utilized the AMT imaging surveys to analyze the subsurface fault systems at the tip of Okinawa Trough in the Ilan plain of Northeastern Taiwan. In addition to the land application, the special issue also includes research paper regarding the marine EM studies, such as the towed CSEM methods (Chen et al. 2020) and the DC resistivity/Spontaneous potential surveys with AUVs and ASV 
(Kasaya et al. 2020). We hope to initiate a gateway for further promoting the electromagnetic exploration researches through the special issue, and to shed a light on the future improvements in the related studies.

\section{REFERENCES}

Abdallah, S., M. Utsugi, K. Aizawa, M. Uyeshima, W. Kanda, T. Koyama, and T. Shiotani, 2020: Threedimensional electrical resistivity structure of the Kuju volcanic group, Central Kyushu, Japan revealed by magnetotelluric survey data. J. Volcanol. Geotherm. Res., 400, 106898, doi: 10.1016/j.jvolgeores.2020.106898. [Link]

Altdorff, D., N. Schliffke, M. Riedel, V. Schmidt, J. van der Kruk, H. Vereecken, J. B. Stoll, and M. Becken, 2014: UAV-borne electromagnetic induction and groundpenetrating radar measurements: A feasibility test. Water Resour. Res., 42, W11403.

Amiri, A., K. Tong, and K. Chetty, 2012: Feasibility study of multi-frequency Ground Penetrating Radar for rotary UAV platforms. IET International Conference on Radar Systems (Radar 2012), Institution of Engineering and Technology, Glasgow, UK, doi: 10.1049/ cp.2012.1590. [Link]

Annan, A. P., 2009: Chapter 1 - Electromagnetic Principles of Ground Penetrating Radar. In: Jol, H. M. (Ed.), Ground Penetrating Radar Theory and Applications: Theory and Applications, Elsevier, Amsterdam, 1-40, doi: 10.1016/B978-0-444-53348-7.00001-6. [Link]

Baba, K., H. Utada, T. Goto, T. Kasaya, H. Shimizu, and N. Tada, 2010: Electrical conductivity imaging of the Philippine Sea upper mantle using seafloor magnetotelluric data. Phys. Earth Planet. Inter., 183, 44-62, doi: 10.1016/j.pepi.2010.09.010. [Link]

Baker, G. S., T. E. Jordan, and J. Pardy, 2007: An introduction to ground penetrating radar (GPR). In: Baker, G. S. and H. M. Jol (Eds.), Stratigraphic Analyses Using GPR, Volume 432, Geological Society of America, doi: 10.1130/2007.2432(01). [Link]

Bartington, G. and C. E. Chapman, 2004: A high-stability fluxgate magnetic gradiometer for shallow geophysical survey applications. Archaeol. Prospect., 11, 1934, doi: 10.1002/arp.219. [Link]

Bin, L., L. Zhengyu, L. Shucai, N. Lichao, S. Maoxin, S. Huaifeng, F. Kerui, Z. Xinxin, and P. Yonghao, 2017: Comprehensive surface geophysical investigation of karst caves ahead of the tunnel face: A case study in the Xiaoheyan section of the water supply project from Songhua River, Jilin, China. J. Appl. Geophys., 144, 37-49, doi: 10.1016/j.jappgeo.2017.06.013. [Link]

Cagniard, L., 1953: Basic theory of the magneto-telluric method of geophysical prospecting. Geophysics, 18, 605-635, doi: 10.1190/1.1437915. [Link]
Campbell, N. and E. Atekwana, 2018: Evaluating the efficacy of magnetic sensors in smartphones for geophysical investigations. SEG Technical Program Expanded Abstracts 2018, Society of Exploration Geophysicists, Anaheim, California, 2582-2586, doi: 10.1190/segam2018-2998607.1. [Link]

Chang, P.-Y., G.-R. Ho, C.-C. Chen, H.-L. Hsu, C.-S. Chen, and E.-C. Yeh, 2020: An analysis of the subsurface fault systems with audiomagnetotelluric surveys in the western Ilan Plain of NE Taiwan. Terr. Atmos. Ocean. Sci., 31, 551-564, doi: 10.3319/TAO.2020.02.17.01. [Link]

Chen, C. and C. Chen, 1998: Preliminary result of magnetotelluric soundings in the fold-thrust belt of Taiwan and possible detection of dehydration. Tectonophysics, 292, 101-117, doi: 10.1016/s0040-1951(98)00059-6. [Link]

Chen, C.-S., 1999: TEM investigations of aquifers in the southwest coast of Taiwan. Ground Water, 37, 890896, doi: 10.1111/j.1745-6584.1999.tb01188.x. [Link]

Chen, K., W.-B. Wei, M. Deng, Z.-L. Wu, and G. Yu, 2015: A seafloor electromagnetic receiver for marine magnetotellurics and marine controlled-source electromagnetic sounding. Appl. Geophys., 12, 317-326, doi: 10.1007/s11770-015-0494-0. [Link]

Chen, K., M. Deng, P. Yu, Q. Yang, X. Luo, and X. Yi, 2020: A nearseafloor-towed CSEM receiver for deeper target prospecting. Terr. Atmos. Ocean. Sci., 31, 565577, doi: 10.3319/TAO.2020.08.03.01. [Link]

Chen, W., G. Xue, N. Zhou, D. Tang, D. Hou, Y. He, K. Lei, K. Chen, and H. Li, 2019: Delineating ore-forming rock using a frequency domain controlled-source electromagnetic method. Ore Geol.Rev., 115, 103167, doi: 10.1016/j.oregeorev.2019.103167. [Link]

Choi, J., T. J. Lee, J. Yang, S. K. Lee, I. H. Park, and Y. Song, 2013: Three-dimensional interpretation considering the static and the sea-effects of magnetotelluric data obtained in Jeju, Korea. J. Appl. Geophys., 98, 5461, doi: 10.1016/j.jappgeo.2013.07.003. [Link]

Cockett, R., S. Kang, L. J. Heagy, A. Pidlisecky, and D. W. Oldenburg, 2015: SimPEG: An open source framework for simulation and gradient based parameter estimation in geophysical applications. Comput. Geosci., 85, 142-154, doi: 10.1016/j.cageo.2015.09.015. [Link]

Constable, S., 2013: Instrumentation for marine magnetotelluric and controlled source electromagnetic sounding. Geophys. Prospect., 61, 505-532, doi: 10.1111/j.13652478.2012.01117.x. [Link]

Du, S., Y. Zhang, Y. Pei, K. Jiang, L. Rong, C. Yin, Y. Ji, and X. Xie, 2018: Study of transient electromagnetic method measurements using a superconducting quantum interference device as B sensor receiver in polarizable survey area. Geophysics, 83, E111-E116, doi: 10.1190/geo2017-0197.1. [Link] 
Duan, S., Y. Li, J. Pei, T. Zhao, Z. Wu, B. Han, X. Yu, L. Liu, J. Chen, and Z. Xu, 2020: Carbonate imaging with magnetotellurics in a shallow-water environment, South Yellow Sea, China. J. Appl. Geophys., 178, 104076, doi: 10.1016/j.jappgeo.2020.104076. [Link]

Feng, H. and K. Wang, 2011: Study on Environmental Noise of the Mine TEM Detection System and Development of the Induction Probe. Procedia Earth and Planetary Science, 3, 477-484, doi: 10.1016/j.proeps.2011.09.123. [Link]

Feng, S.-J., Y. Zhao, X.-L. Zhang, and Z.-B. Bai, 2020: Leachate leakage investigation, assessment and engineering countermeasures for tunneling underneath a MSW landfill. Eng. Geol., 265, 105447, doi: 10.1016/j. enggeo.2019.105447. [Link]

Fernández, M. G., Y. A. Lopez, A. A. Arboleya, B. G. Valdes, Y. R. Vaqueiro, F. L.-H. Andres, and A. P. Garcia, 2018: Synthetic aperture radar imaging system for landmine detection using a ground penetrating radar on board a unmanned aerial vehicle. IEEE Access, 6, 45100-45112, doi: 10.1109/access.2018.2863572. [Link]

Fok, V. A. and V. P. Bursian, 1926: Electromagnetic Field of a Current in a Circuit with Two Grounds. Zh. Fiz. Khim. Ob, 58.

Fuji-ta, K., S. Fujiwara, M. Ichiki, and Y. Makino, 2002: One-dimensional resistivity modeling of NE Japan from stationary wide-band magnetotelluric data. Tectonophysics, 359, 371-380, doi: 10.1016/s00401951(02)00534-6. [Link]

Gao, J., H. Zhang, H. Zhang, S. Zhang, and Z. Cheng, 2020: Three-dimensional magnetotelluric imaging of the SE Gonghe Basin: Implication for the orogenic uplift in the northeastern margin of the Tibetan plateau. Tectonophysics, 789, 228525, doi: 10.1016/j. tecto.2020.228525. [Link]

Han, N., M. J. Nam, H. J. Kim, T. J. Lee, Y. Song, and J. H. Suh, 2009: Three-dimensional inversion of magnetotelluric data including sea effects obtained in Pohang, Korea. J. Appl. Geophys., 68, 533-545, doi: 10.1016/j. jappgeo.2009.04.001. [Link]

Hatakeyama, H. and M. Hirayama, 1934: On the Phase Difference Between the Pulsation of Terrestrial Magnetism and of Earth Current. J. Meteorol. Soc. Jpn., 12, 449-459, doi: 10.2151/jmsj1923.12.9_449. [Link]

He, G.-1., H.-m. Kang, G.-j. Wang, T.-j. Xiao, and X.-y. Yang, 2020: Application of audiomagnetotellurics to delineate an iron deposit in the Liguo area, eastern China. Solid Earth Sciences, 5, 83-92, doi: 10.1016/j. sesci.2020.02.001. [Link]

Hirayama, M., 1934: On the relations between the variations of Earth potential gradient and terrestrial magnetism. J. Meteorol. Soc. Jpn., 12, 16-22, doi: 10.2151/ jmsj1923.12.1_16. [Link]
Hsu, S.-K., C.-W. Chiang, R. L. Evans, C.-S. Chen, S.-D. Chiu, Y.-F. Ma, S.-C. Chen, C.-H. Tsai, S.-S. Lin, and Y. Wang, 2014: Marine controlled source electromagnetic method used for the gas hydrate investigation in the offshore area of SW Taiwan. J. Asian Earth Sci., 92, 224-232, doi: 10.1016/j.jseaes.2013.12.001. [Link]

Hu, Y., D. Li, B. Yuan, G. Suo, and Z. Liu, 2020: Application of pseudo-random frequency domain electromagnetic method in mining areas with strong interferences. Trans. Nonferrous Met. Soc. China, 30, 774-788, doi: 10.1016/s1003-6326(20)65253-0. [Link]

Ikeda, M., S. Kato, N. Nishizaka, Y. Ohno, K. Matsuo, and M. Kishimoto, 2013: Magnetotelluric imaging of the Median Tectonic Line in western Shikoku, southwest Japan: Implications of the fault-related low-resistivity zone. Tectonophysics, 601, 78-86, doi: 10.1016/j.tecto.2013.04.026. [Link]

Jomori, A., N. Jomori, A. Jomori, T. Kondo, Y. Yuuki, and A. Shinsei, 2020: Development of airborne transient electromagnetics system using Drone: D-GREATEM, D-TEM[GLS], D-TEM[ALS]. BUTSURI-TANSA (Geophysical Exploration), 73, 83-95, doi: 10.3124/ segj.73.83. [Link]

Kai, C., J. Sheng, and S. Wang, 2017: Electromagnetic receiver with capacitive electrodes and triaxial induction coil for tunnel exploration. Earth Planets Space, 69, 123, doi: 10.1186/s40623-017-0706-3. [Link]

Kasaya, T. and T. Goto, 2009: A small ocean bottom electromagnetometer and ocean bottom electrometer system with an arm-folding mechanism (Technical Report). Explor. Geophys., 40, 41-48, doi: 10.1071/ eg08118. [Link]

Kasaya, T., H. Iwamoto, Y. Kawada, and T. Hyakudome, 2020: Marine DC resistivity and self-potential survey in the hydrothermal deposit areas using multiple AUVs and ASV. Terr. Atmos. Ocean. Sci., 31, 579-588, doi: 10.3319/TAO.2019.09.02.01. [Link]

Key, K. and S. Constable, 2011: Coast effect distortion of marine magnetotelluric data: Insights from a pilot study offshore northeastern Japan. Phys. Earth Planet. Inter., 184, 194-207, doi: 10.1016/j.pepi.2010.11.008. [Link]

Klipsch, P. W., 1939: Recent developments in Eltran prospecting. Geophysics, 4, 283-291, doi: 10.1190/1.1440505. [Link]

Knudsen, D. J., J. K. Burchill, S. C. Buchert, A. I. Eriksson, R. Gill, J.-E. Wahlund, L. Åhlen, M. Smith, and B. Moffat, 2017: Thermal ion imagers and Langmuir probes in the Swarm electric field instruments. J. Geophys. Res., 122, 2655-2673, doi: 10.1002/2016ja022571. [Link]

Koppenjan, S., 2009: Chapter 3 - Ground Penetrating Radar Systems and Design. In: Jol, H. M. (Ed.), Ground Penetrating Radar Theory and Applications: Theory and Applications, Elsevier, Amsterdam, 73-97, doi: 
10.1016/B978-0-444-53348-7.00003-X. [Link]

Layeghi, A., H. Latifi, and O. Frazao, 2014: Magnetic field sensor based on nonadiabatic tapered optical fiber with magnetic fluid. IEEE Photonics Technol. Lett., 26, 1904-1907, doi: 10.1109/lpt.2014.2341662. [Link]

Li, C., Y. Su, E. Pettinelli, S. Xing, C. Ding, J. Liu, X. Ren, S. E. Lauro, F. Soldovieri, X. Zeng, X. Gao, W. Chen, S. Dai, D. Liu, G. Zhang, W. Zuo, W. Wen, Z. Zhang, X. Zhang, and H. Zhang, 2020a: The Moon's farside shallow subsurface structure unveiled by Chang'E-4 Lunar Penetrating Radar. Sci. Adv., 6, eaay6898, doi: 10.1126/sciadv.aay6898. [Link]

Li, G., X. Liu, J. Tang, J. Li, Z. Ren, and C. Chen, 2020b: De-noising low-frequency magnetotelluric data using mathematical morphology filtering and sparse representation. J. Appl. Geophys., 172, 103919, doi: 10.1016/j.jappgeo.2019.103919. [Link]

Li, J., X. Zhang, and J. Tang, 2020c: Noise suppression for magnetotelluric using variational mode decomposition and detrended fluctuation analysis. J. Appl. Geophys., 180, 104127, doi: 10.1016/j.jappgeo.2020.104127. [Link]

Li, S., B. Liu, X. Xu, L. Nie, Z. Liu, J. Song, H. Sun, L. Chen, and K. Fan, 2017: An overview of ahead geological prospecting in tunneling. Tunn. Undergr. Space Technol., 63, 69-94, doi: 10.1016/j.tust.2016.12.011. [Link]

Liang, H., R. Gao, S. Xue, and J. Han, 2020a: Electrical structure of the middle Qilian Shan revealed by 3-D inversion of magnetotelluric data: New insights into the growth and deformation in the Northeastern Tibetan Plateau. Tectonophysics, 789, 228523, doi: 10.1016/j. tecto.2020.228523. [Link]

Liang, H., R. Gao, S. Xue, and Z. Yang, 2020b: Lithospheric electrical structure between the Erguna and Xing' an blocks: Evidence from broadband and long period magnetotelluric data. Phys. Earth Planet. Inter., 308, 106586, doi: 10.1016/j.pepi.2020.106586. [Link]

Liu, F., L. Huang, L. Liu, J. Li, Z. Geng, Q. Zhang, and G. Fang, 2016: A New Semi-airborne Transient Electromagnetic System and Application of Detecting Underground Conductor in East Ujimqin Banner, China. 7th International Conference on Environment and Engineering Geophysics \& Summit Forum of Chinese Academy of Engineering on Engineering Science and Technology, Beijing, China, Atlantis Press, doi: 10.2991/iceeg-16.2016.113. [Link]

Liu, R., J. Liu, C. Liu, R. Guo, H. Wang, and Z. Liu, 2020a: A feasibility study of the wide-field electromagnetic method for hidden ore deposits prospecting. J. Appl. Geophys., 179, 104121, doi: 10.1016/j.jappgeo.2020.104121. [Link]

Liu, Y., S. Liu, Z. Jiang, and S. Chen, 2020b: Analysis on full-domain apparent resistivity characteristics of ground-tunnel transient electromagnetic method. Terr. Atmos. Ocean. Sci., 31, 539-549, doi: 10.3319/ TAO.2019.07.02.02. [Link]

Mitsuhata, Y., T. Uchida, K. Matsuo, A. Marui, and K. Kusunose, 2006: Various-scale electromagnetic investigations of high-salinity zones in a coastal plain. Geophysics, 71, B167-B173, doi: 10.1190/1.2335658. [Link]

Mogi, T., A. Jomori, N. Jomori, Y. Azuma, and E. Y. Fomenko, 2005: Development of Grounded Electrical Source Airborne Transient EM (GREATEM) Survey System and Its Application to Investigating a Volcano Structure. American Geophysical Union, Fall Meeting 2005, abstract id. GP41B-0878.

Nabighian, M. N., 1988: Electromagnetic Methods in Applied Geophysics, Society of Exploration Geophysicists, $972 \mathrm{pp}$.

Nabighian, M. N. and J. C. Macnae, 1991: Chapter 6: Time Domain Electromagnetic Prospecting Methods. In: Nabighian, M. N. (Ed.), Electromagnetic Methods in Applied Geophysics: Volume 2, Application, Parts A and B, Society of Exploration Geophysicists, Oklahoma, 427-514, doi: 10.1190/1.9781560802686.ch6. [Link]

Noh, K., Y. Chung, S. J. Seol, J. Byun, and T. Uchida, 2014: Three-dimensional inversion of CSEM data: Water leak detection using a small-loop EM method. J. Appl. Geophys., 102, 134-144, doi: 10.1016/j.jappgeo.2014.01.001. [Link]

Paál, G., 1965: Ore prospecting based on VLF-radio signals. Geoexploration, 3, 139-147, doi: 10.1016/00167142(65)90016-5. [Link]

Paterson, N. R. and V. Ronka, 1971: Five years of surveying with the Very Low Frequency-Electro magnetics method. Geoexploration, 9, 7-26, doi: 10.1016/00167142(71)90085-8. [Link]

Phillips, W. J. and W. E. Richards, 1975: Study of the effectiveness of the VLF method for the location of narrowmineralized fault zones. Geoexploration, 13, 215-226, doi: 10.1016/0016-7142(75)90024-1. [Link]

Podgorski, J. E., E. Auken, C. Schamper, A. Vest Christiansen, T. Kalscheuer, and A. G. Green, 2013: Processing and inversion of commercial helicopter time-domain electromagnetic data for environmental assessments and geologic and hydrologic mapping. Geophysics, 78, E149-E159, doi: 10.1190/geo2012-0452.1. [Link]

Ramasamy, N. and I. Mohanty, 2020: Characterization of TDEM System with SQUID and Fluxgate Magnetometers for Geophysical Applications. IEEE Trans. Appl. Supercond., 30, 1-8, doi: 10.1109/tasc.2019.2957198. [Link]

Reynolds, J. M., 2011: An Introduction to Applied and Environmental Geophysics, 2nd Edition, John Wiley \& Sons, $710 \mathrm{pp}$. 
Rücker, C., T. Günther, and F. M. Wagner, 2017: pyGIMLi: An open-source library for modelling and inversion in geophysics. Comput. Geosci., 109, 106-123, doi: 10.1016/j.cageo.2017.07.011. [Link]

Ryang, W. H., S. K. Chough, J. S. Kim, and H. Shon, 1999: Three-dimensional configuration of a pull-apart basin from high-resolution magnetotelluric profiling: Eumsung Basin (Cretaceous), Korea. Sediment. Geol., 129, 101-109, doi: 10.1016/s0037-0738(99)00091-3. [Link]

Sasaki, Y., M.-J. Yi, and J. Choi, 2014: 2D and 3D separate and joint inversion of airborne ZTEM and ground AMT data: Synthetic model studies. J. Appl. Geophys., 104, 149-155, doi: 10.1016/j.jappgeo.2014.02.017. [Link]

Sasaki, Y., M.-J. Yi, J. Choi, and J.-S. Son, 2015: Frequency and time domain three-dimensional inversion of electromagnetic data for a grounded-wire source. J. Appl. Geophys., 112, 106-114, doi: 10.1016/j.jappgeo.2014.09.016. [Link]

Sato, M. and T. Takayama, 2007: A novel directional borehole radar system using optical electric field sensors. IEEE Trans. Geosci. Remote Sensing, 45, 2529-2535, doi: 10.1109/tgrs.2007.898421. [Link]

Seama, N., K. Baba,H. Utada,H.Toh, N. Tada,M. Ichiki, and T. Matsuno, 2007: 1-D electrical conductivity structure beneath the Philippine Sea: Results from an ocean bottom magnetotelluric survey. Phys. Earth Planet. Inter., 162, 2-12, doi: 10.1016/j.pepi.2007.02.014. [Link]

Šipoš, D. and D. Gleich, 2020: A Lightweight and LowPower UAV-Borne Ground Penetrating Radar Design for Landmine Detection. Sensors, 20, 2234, doi: 10.3390/s20082234. [Link]

Sun, X., Y. Zhan, L. Zhao, X. Chen, J. Sun, C. Li, T. Cui, and J. Han, 2019: Electrical structure of the Kunlun-Qinling fault system, northeastern Tibetan Plateau, inferred from 3-D inversion of magnetotelluric data. J. Asian Earth Sci., 181, 103910, doi: 10.1016/j. jseaes.2019.103910. [Link]

Sundberg, K. and F. H. Hedstrom, 1934: Structural investigation by electromagnetic methods. Proceedings World Petroleum Conference 1934, Volume V, Institute of Petroleum Technologists, 102-110.

Tikhonov, A. N., 1950: On determining electrical characteristics of the deep layers of the Earth's crust. Dokl. Akad. Nauk. SSSR, 73, 295-297.

Ueda, T., Y. Mitsuhata, T. Uchida, A. Marui, and K. Ohsawa, 2014: A new marine magnetotelluric measurement system in a shallow-water environment for hydrogeological study. J. Appl. Geophys., 100, 23-31, doi: 10.1016/j.jappgeo.2013.10.003. [Link]

Wang, M., M. Deng, Z. Wu, X. Luo, J. Jing, and K. Chen, 2017: The deep-tow marine controlled-source electromagnetic transmitter system for gas hydrate exploration. J. Appl. Geophys., 137, 138-144, doi: 10.1016/j. jappgeo.2016.12.019. [Link]

Wang, T.-P., C.-C. Chen, L.-T. Tong, P.-Y. Chang, Y.-C. Chen, T.-H. Dong, H.-C. Liu, C.-P. Lin, K.-H. Yang, C.-J. Ho, and S.-N. Cheng, 2015: Applying FDEM, ERT and GPR at a site with soil contamination: A case study. J. Appl. Geophys., 121, 21-30, doi: 10.1016/j. jappgeo.2015.07.005. [Link]

Wang, T.-P., Y.-T. Chen, C.-C. Chen, T.-H. Tung, S.-N. Cheng, and C.-Y. Yu, 2020: Application of cross-hole electrical resistivity tomography to groundwater contaminated remediation site. Terr. Atmos. Ocean. Sci., 31, 507-521, doi: 10.3319/TAO.2019.06.17.01. [Link]

Wang, X. and S. Liu, 2017: Noise suppressing and direct wave arrivals removal in GPR data based on Shearlet transform. Signal Process., 132, 227-242, doi: 10.1016/j.sigpro.2016.05.007. [Link]

Xu, F.-J., L.-J. Yan, K. Xiang, X.-L. Tong, and X.-B. Xie, 2020: Predicting the characteristic parameters of shale sweet-spot with complex resistivity. Terr. Atmos. Ocean. Sci., 31, 497-505, doi: 10.3319/ TAO.2020.03.22.01. [Link]

Ye, G., H. Fu, S. Jin, and W. Wei, 2020: Magnetotelluric study of the mechanism of the Abaga and Dalinor volcanic groups in Central Inner Mongolia, China. Phys. Earth Planet. Inter., 308, 106570, doi: 10.1016/j. pepi.2020.106570. [Link]

Yen, N.-T., T.-L. Lin, L.-R. Liao, P.-Y. Chang, and H. Mittal, 2020: Illustrate mud-fluid conduits and their variety using resistivity image profiling method in Southwest Taiwan. Terr. Atmos. Ocean. Sci., 31, 523-537, doi: 10.3319/TAO 2019.07.02.01. [Link]

Zeng, Q., Q. Di, T. Liu, G. Li, C. Yu, P. Shen, H. Liu, and J. Ye, 2020: Explorations of gold and lead-zinc deposits using a magnetotelluric method: Case studies in the Tianshan-Xingmeng Orogenic Belt of Northern China. Ore Geol. Rev., 117, 103283, doi: 10.1016/j.oregeorev.2019.103283. [Link]

Zhang, L., C. Zhao, P. Yu, Y. Xiang, X. Peng, T. Koyama, and W. Yang, 2020: The electrical conductivity structure of the Tarim basin in NW China as revealed by three-dimensional magnetotelluric inversion. J. Asian Earth Sci., 187, 104093, doi: 10.1016/j. jseaes.2019.104093. [Link] 